\title{
The effect of hat on phototherapy-induced hypocalcemia in jaundiced full-term neonates
}

\author{
This article was published in the following Dove Press journal: \\ Research and Reports in Neonatology \\ 4 August 2015 \\ Number of times this article has been viewed
}

\section{Zahraa Ezzeldin \\ Yasmeen Mansi \\ Tamer A Abdelhamid \\ Mohamed Sabry}

Department of Pediatrics, Faculty of Medicine, Cairo University, Giza, Egypt
Background: It has been hypothesized that phototherapy leads to increased calcium absorption by the bones through irradiating the pineal gland and reducing melatonin level. There is some evidence that the use of a stockinet cap to cover the head prevents phototherapy-induced hypocalcemia.

Study design: This was a randomized controlled trial, including 124 full-term neonates, weighing $>2,500 \mathrm{~g}$, in the first 7 days of life, who developed a bilirubin level ranging from 15 to $20 \mathrm{mg} / \mathrm{dL}$ and needed treatment with phototherapy. Our neonates were divided into two groups: Group A without the hat, and Group B with the hat. We designed a dark-colored hat that covered the entire head, including the occipital area, ears, and neck, to prevent passage of light. The hat was used from the time of admission and for the 48 hours of treatment with phototherapy. Ca levels were measured on admission and after 48 hours of phototherapy. The variables were compared using Student's $t$-test, chi-square test, and the repeated-measures test.

Results: There was no difference in the mean $\mathrm{Ca}$ levels in the two groups on admission. However, after 48 hours of phototherapy, there was a trend toward an increased Ca level in the group with the hat; $8.74 \pm 0.95 \mathrm{mg} / \mathrm{dL}$ vs $8.51 \pm 0.24 \mathrm{mg} / \mathrm{dL}$ in the control group. Moreover, there was a statistically significant decrease in the incidence of neonates with hypocalcemia in Group B (with hat) in only six cases $(9.7 \%)$, compared to 15 cases $(24.2 \%)$ in Group A (without hat; $P=0.031$ )

Conclusion: Phototherapy-induced hypocalcemia can be prevented by covering the head during phototherapy. This seems to be a safe, effective, and cheap method to prevent hypocalcemia and its complications, with no need for prophylactic administration of calcium.

Keywords: neonatal jaundice, phototherapy-induced hypocalcemia, hat, calcium therapy

\section{Introduction}

Hyperbilirubinemia is the most common abnormal physical finding in the first week of life and is observed in approximately $60 \%$ of term neonates and $80 \%$ of preterm neonates. ${ }^{1}$ Although most jaundiced neonates are otherwise perfectly healthy, they make us anxious because bilirubin is potentially toxic to the central nervous system. ${ }^{2}$

Phototherapy plays a significant role in the treatment and prevention of hyperbilirubinemia in neonates. This relatively common therapy decreases the serum bilirubin level by transforming bilirubin into water-soluble isomers that can be eliminated without conjugation in the liver. ${ }^{3}$ However, this treatment modality may itself result in the development of some complications. ${ }^{4}$

Among these are loose stools, erythematous macular rash, overheating, dehydration, damage to DNA, retinal injury, and a benign condition called bronze baby syndrome
Correspondence: Yasmeen Mansi Department of Pediatrics, Faculty of Medicine, Cairo University Hospitals, Kasr El Ainy St, Cairo II 562, Egypt Emaily_mansi@yahoo.com 
in cholestasis. ${ }^{5}$ Moreover, one of these complications is the induction of hypocalcemia, which can create serious adverse effects, including convulsions, jitteriness, and irritability. ${ }^{5}$

Romagnoli et $\mathrm{al}^{6}$ suggested, for the first time, the association of hypocalcemia with phototherapy in preterm neonates. Similarly, Hakanson et $\mathrm{al}^{7}$ documented this observation in newborn rats. There are few other studies on the hypocalcemic effect of phototherapy. ${ }^{7-9}$

On the basis of the results of animal studies, it has been hypothesized that phototherapy inhibits pineal secretion of melatonin, which blocks the effect of cortisol on bone calcium. Therefore, cortisol increases bone uptake of calcium and induces hypocalcemia. ${ }^{10}$ Other causes suggested for this hypocalcemia include a decreased secretion of parathormone ${ }^{11}$ and a higher urinary excretion of calcium in the phototherapy group. ${ }^{12}$

Some studies have suggested the administration of calcium for this condition, but intravenous calcium therapy may lead to bradycardia, cardiac arrest, and necrosis. On the other hand, monitoring intravenous infusions of calcium is difficult because of the shortage of trained staff. ${ }^{4}$

Phototherapy leads to increased calcium absorption by the bones through irradiating the pineal gland and reducing melatonin level. ${ }^{7}$ There is some evidence that the use of a stockinet cap to cover the head prevents phototherapyinduced hypocalcemia. ${ }^{13}$

We aimed to study the effect of head covering on the serum calcium levels in neonates with hyperbilirubinemia during phototherapy.

\section{Methods}

\section{Patients}

The study was carried out prospectively over an 11-month period (starting from February 2011 to January 2012) at the Helwan General Hospital, Cairo, Egypt. The study was approved by the Ethical Committee for Scientific Research, Pediatric Department, Cairo University, and an informed consent was obtained from all the families.

The study included 124 full-term neonates, weighing $>2,500 \mathrm{~g}$, in the first 7 days of life, who developed a bilirubin level from 15 to $20 \mathrm{mg} / \mathrm{dL}$ and needed treatment with phototherapy according to the guidelines of the American Academy of Pediatrics (AAP). ${ }^{14}$ Infants nearing or at exchange level should be excluded as keeping the hat on covers a significant ( $8 \%-10 \%$ of the body surface area) and acute bilirubin encephalopathy/kernicterus is a more devastating long-term consequence than hypocalcemia.

Neonates were excluded from the study if they developed jaundice during the first 24 hours of life; if they suffered from congenital anomalies, sepsis, hemolytic anemias, or apneas; or if they had an Apgar score $<7$. Moreover, infants whose mothers were diabetic, had history of taking anticonvulsants (phenobarbital), or had history of hyperthyroidism or signs and symptoms related to this condition at the time of pregnancy were not eligible for inclusion in our study.

\section{Randomization}

All enrolled infants were randomly assigned to either the group using a hat or the group not using it, according to a computergenerated sequence. After enrollment, cases were sequentially arranged and plotted on the random number tables to determine to which group they will be assigned. Neonates were divided into two equal groups: Group A: 62 infants under routine phototherapy without hats; and Group B: 62 infants using hats that covered their heads during phototherapy.

\section{Intervention}

The demographic and clinical variables were recorded, including birth weight, sex, gestational age, duration of phototherapy, onset of jaundice, maternal blood group and Rh status, Apgar score, and family history of jaundice.

In addition to routine investigation, we measured their serum calcium and total serum bilirubin levels, before and after 48 hours of phototherapy.

Ca level measurement needed $2 \mathrm{~mL}$ blood sample from a peripheral vein. Centrifugation was used to obtain the serum, and then $\mathrm{Ca}$ level was measured in the serum using Beckman CX9 PRO.

We used a preset definition for hypocalcemia: total serum calcium level $<8 \mathrm{mg} / \mathrm{dL}$ was considered hypocalcemia. ${ }^{15}$

Bilirubin levels were measured and recorded at the baseline and at 48 hours after phototherapy. Bilirubin was measured using the Jendrassik-Grof method. The period that the infant could not receive phototherapy for various reasons (feeding, physical examination, and blood sampling) was noted by the staff, and the absolute phototherapy duration and rate were calculated.

The neonates were clinically assessed for features of hypocalcemia, ie, jitteriness, irritability/excitability, lethargy, and convulsions, as well as for other complications such as rash, loose stools, fever, and dehydration. Hypocalcemia in the affected neonates was managed with oral or intravenous calcium.

\section{The hat}

Routine phototherapy was used for the control group, and the occipital area of the neonates was covered by a hat during phototherapy in the case group. 
We designed a dark-colored hat that covered the entire head, including the occipital area, ears, and neck, to prevent passage of light. The hat was used from the time of admission and for the 48 hours of treatment with phototherapy (Figure 1).

\section{Phototherapy}

A conventional phototherapy equipment, containing four blue light fluorescent lamps with wavelengths of $410-470 \mathrm{~nm}$, was placed at a distance of $30-40 \mathrm{~cm}$. We used the AAP guidelines for phototherapy. The irradiance during phototherapy was measured and maintained consistent between the two groups.

\section{Outcome measures}

The primary outcome measure was the level of calcium after phototherapy in both groups.

The secondary outcome measure was the incidence of phototherapy-induced hypocalcemia in our study population; we also assessed the development of symptoms or signs related to hypocalcemia, such as jitteriness or convulsions.

\section{Sample size calculation}

We planned a randomized controlled study with one control per case. A previous study indicated that the occurrence of hypocalcemia among controls is $30 \% .{ }^{16}$ Type I error probability associated with this test was set to 0.05 . We used an uncorrected chi-squared $\left(\chi^{2}\right)$ statistic to evaluate this null hypothesis.

1. If rate in experimental subjects is $0.15 \%$, the sample size will be 103 cases and 103 controls.

2. If rate in experimental subjects is $0.10 \%$, the sample size will be 62 cases and 62 controls.

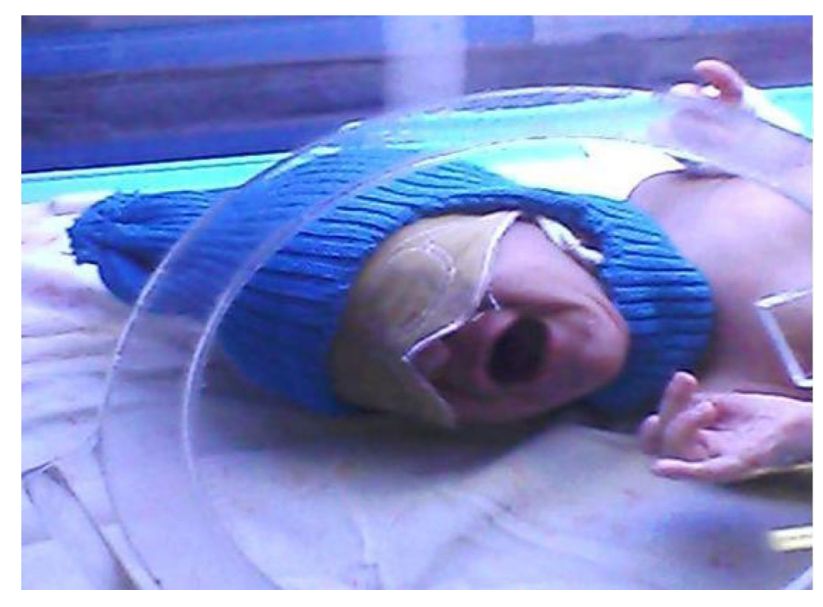

Figure I Design of the hat.

\section{Statistical methods}

Data were statistically described in terms of mean \pm standard deviation (SD), median and range, or frequencies (number of cases) and percentages when appropriate. Comparison of numerical variables between the study groups was done using the Student's $t$-test for independent samples. For comparing categorical data, the $\chi^{2}$ test was used. Exact test was used instead when the expected frequency was $<5$. Multivariate logistic regression model was used to test for independent association with regard to hypocalcemia. $P$-values $<0.05$ were considered statistically significant. All statistical calculations were conducted using the computer program SPSS (Statistical Package for the Social Science; SPSS Inc., Chicago, IL, USA) version 15 for Microsoft Windows.

\section{Results}

We included in our study 124 full-term neonates with hyperbilirubinemia treated with phototherapy (Figure 2). Their mean body weight was $3,224 \pm 318 \mathrm{~g}$ (ranged from 2,600 to $4,120 \mathrm{~g}$ ) and their mean gestational age was $39.29 \pm 0.75$ weeks. The onset of their jaundice was at approximately $2.67 \pm 0.68$ days. Their mean age on admission was $4.08 \pm 0.83$ days.

They had a mean total bilirubin level on admission of $17.64 \pm 0.99 \mathrm{mg} / \mathrm{dL}$ and a level of $10.41 \pm 0.98 \mathrm{mg} / \mathrm{dL} 48$ hours after phototherapy. Their mean $\mathrm{Ca}$ level on admission was $8.68 \pm 0.79 \mathrm{mg} / \mathrm{dL}$ (range from 7.8 to $10.5 \mathrm{mg} / \mathrm{dL}$ ) and after 48 hours, it reached $8.54 \pm 0.82 \mathrm{mg} / \mathrm{dL}$ (ranging from 6.8 to $10.3 \mathrm{mg} / \mathrm{dL}$ ).

There were no significant differences in the clinical characteristics of the two groups, namely, Group A without the hat and Group B with the hat (Table 1).

There was no difference in the mean Ca levels in the two groups on admission. However, after 48 hours of phototherapy, there was a trend toward an increased Ca level in the group with the hat $(8.74 \pm 0.95$ vs $8.51 \pm 0.24 \mathrm{mg} / \mathrm{dL}$ in the control group).

Moreover, the mean change in Ca level was statistically, significantly lower in the group without the hat, whereas in Group B, there was no significant change in the $\mathrm{Ca}$ level (Table 2).

We found a statistically significant difference between the two groups with regard to the percentage of neonatal hypocalcemia after phototherapy. Neonates with hypocalcemia represented 15 cases (24.2\%) in Group A, whereas in Group B, only six cases $(9.7 \%)$ presented with hypocalcemia after phototherapy $(P=0.031$; Table 3$)$. 


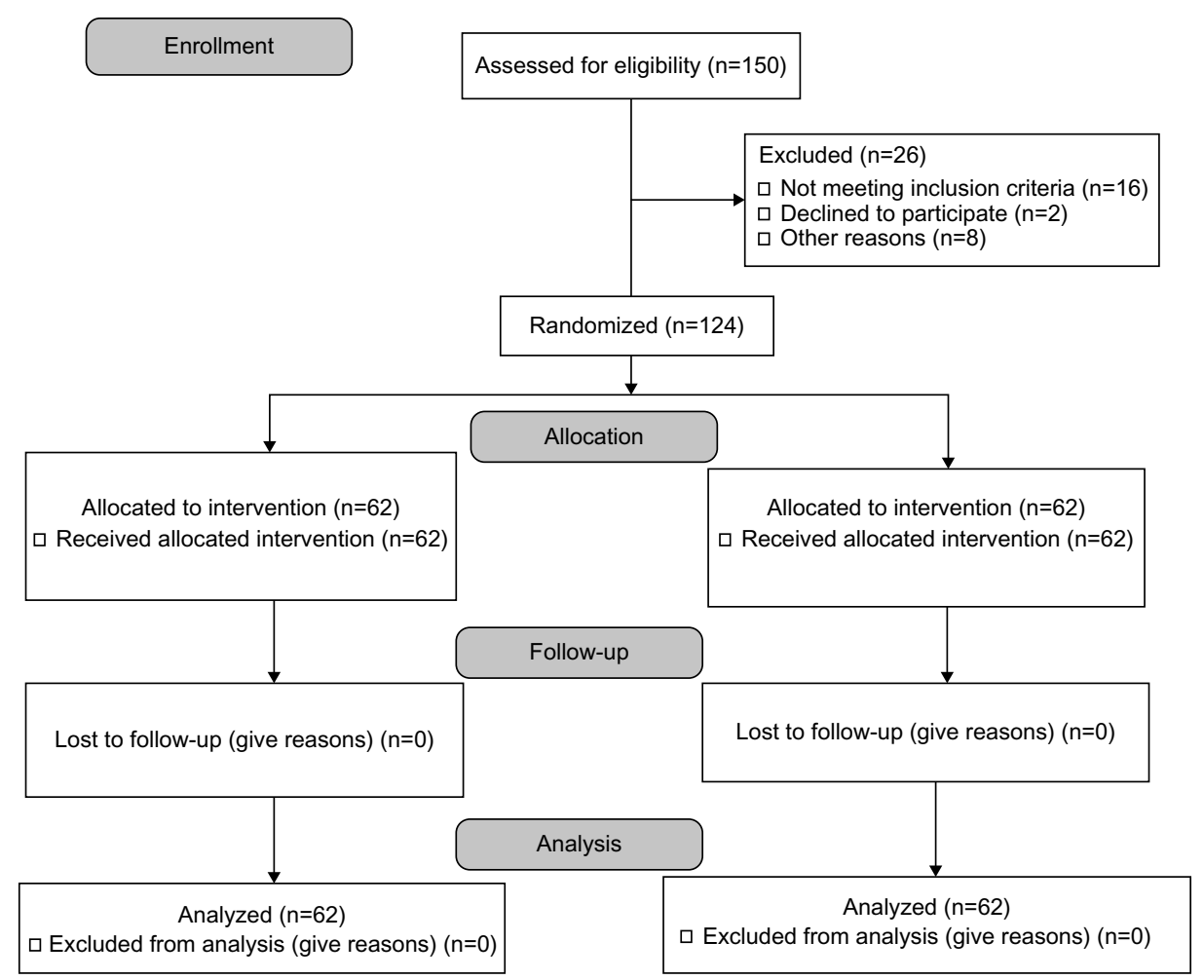

Figure 2 CONSORT flow diagram.

Abbreviation: CONSORT, CONsolidated Standards Of Reporting Trials.

Although there was no significant difference in the risk of developing jitteriness between the control and study groups, two neonates in the control group developed hypocalcemic convulsions, with Ca level being $<7 \mathrm{mg} / \mathrm{dL}$, which necessitated intravenous administration of calcium, to control the seizures.

Table I Comparison of clinical and laboratory parameters between the study groups

\begin{tabular}{|c|c|c|c|}
\hline Variable & $\begin{array}{l}\text { Without hat, } \\
\text { mean } \pm S D \\
(\mathrm{~N}=62)\end{array}$ & $\begin{array}{l}\text { With hat, } \\
\text { mean } \pm \mathrm{SD} \\
(\mathrm{N}=62)\end{array}$ & $P$-value \\
\hline Body weight (g) & $3,188 \pm 336$ & $3,260 \pm 298$ & 0.211 \\
\hline Gestational age (weeks) & $39.24 \pm 0.78$ & $39.34 \pm 0.72$ & 0.476 \\
\hline Female infants (\%) & 33 (53.2\%) & $23(37.1 \%)$ & 0.071 \\
\hline Male infants (\%) & $29(46.8 \%)$ & 39 (62.9\%) & 0.001 \\
\hline $\begin{array}{l}\text { Day of onset of } \\
\text { jaundice (days) }\end{array}$ & $2.56 \pm 0.56$ & $2.77 \pm 0.78$ & 0.088 \\
\hline $\begin{array}{l}\text { Mean age on admission } \\
\text { (days) }\end{array}$ & $3.98 \pm 0.84$ & $4.18 \pm 0.82$ & 0.197 \\
\hline $\begin{array}{l}\text { Mean total bilirubin on } \\
\text { admission }(\mathrm{mg} / \mathrm{dL})\end{array}$ & $17.655 \pm \mid$ & $17.629 \pm 0.99$ & 0.886 \\
\hline $\begin{array}{l}\text { Mean total bilirubin } \\
\text { after } 48 \text { hours ( } \mathrm{mg} / \mathrm{dL})\end{array}$ & $10.503 \pm 0.88$ & $10.324 \pm 1.07$ & 0.309 \\
\hline $\begin{array}{l}\text { Mean Ca on admission } \\
(\mathrm{mg} / \mathrm{dL})\end{array}$ & $8.68 \pm 0.63$ & $8.69 \pm 0.54$ & 0.924 \\
\hline $\begin{array}{l}\text { Mean Ca after } 48 \text { hours } \\
(\mathrm{mg} / \mathrm{dL})\end{array}$ & $8.5 I \pm 0.24$ & $8.74 \pm 0.95$ & 0.067 \\
\hline
\end{tabular}

Abbreviation: SD, standard deviation.

\section{Discussion}

We detected hypocalcemia in 15 (24\%) of our neonates 48 hours after phototherapy in the group without the hat and in six $(9.7 \%)$ neonates with the hat after the same period of time.

The incidence of hypocalcemia in our study group without the hat is similar to the results of previous studies that reported that the incidence of hypocalcemia after 48 hours of phototherapy was $14.4 \%{ }^{17}$ and that $38 \%$ of neonates had hypocalcemia $(\mathrm{Ca} \leq 7.5 \mathrm{mg} / \mathrm{dL}) 48$ hours after phototherapy, ${ }^{18}$ with proportion reaching up to $55 \%$ in preterm neonates who had been subjected to phototherapy. ${ }^{16}$

There are several theories to explain the effect of phototherapy on calcium metabolism. Phototherapy decreases melatonin level and corticosterone secretion. ${ }^{17}$ Melatonin stimulates secretion of corticosterone, which decreases calcium absorption by bones. Phototherapy leads to inhibition of pineal gland via transcranial illumination, resulting in a decline in melatonin level and, as a result, hypocalcemia develops. ${ }^{17}$

The statistically significant decrease in the incidence of hypocalcemia after the application of a hat was well evident in our study. In the group without hats, there was a decrease in $\mathrm{Ca}$ level after 48 hours of phototherapy ( $8.68 \pm 0.63$ and $8.51 \pm 0.24 \mathrm{mg} / \mathrm{dL}$, respectively), and this change in Ca level was statistically significant $(P=0.049)$. 
Table 2 Changes in Ca levels in the two groups on admission and 48 hours after phototherapy

\begin{tabular}{lllll}
\hline Variable & $\begin{array}{l}\text { Mean Ca on } \\
\text { admission }(\mathbf{m g} / \mathbf{d L})\end{array}$ & $\begin{array}{l}\text { Mean Ca after } \\
\mathbf{4 8} \text { hours }(\mathbf{m g} / \mathbf{d L})\end{array}$ & $\begin{array}{l}\text { Mean difference } \\
(\mathbf{m g} / \mathbf{d L})\end{array}$ \\
\hline Without hat, mean \pm SD & $8.68 \pm 0.63$ & $8.51 \pm 0.24$ & 0.170 & 0.049 \\
With hat, mean \pm SD & $8.69 \pm 0.54$ & $8.74 \pm 0.95$ & -0.052 & 0.719 \\
\hline
\end{tabular}

Abbreviation: SD, standard deviation.

In the group with the hats, there was no change in $\mathrm{Ca}$ level after phototherapy. The hat blocked the effect of phototherapy by preventing passage of light to the head of the infant.

Our results are consistent with those of two previous studies ${ }^{4,18}$ which had used the same method for prevention of hypocalcemia.

In the study by Ehsanipoor et al, ${ }^{4} 18$ infants (15\%) developed hypocalcemia after starting phototherapy, of whom $77.7 \%$ were in the group without the hat and only $22.2 \%$ were in the group with the hat $(P=0.000)$.

Similar results were noted in another study, ${ }^{17}$ wherein $14(38.8 \%)$ neonates in the control group and only five $(13.8 \%)$ infants in the case group developed hypocalcemia after phototherapy.

Although infants with the hat had a reduced incidence of hypocalcemia, there was no statistically significant reduction in clinical signs of hypocalcemia in the form of jitteriness.

Jitteriness is not the prominent sign of hypocalcemia and occurs in attacks lasting for a short duration and then disappears. More often, it is nonspecific and not related to the severity of hypocalcemia. ${ }^{15}$ Thus, it is hard to assess hypocalcemia clinically, and clinical signs cannot be evaluated properly.

Nevertheless, although the signs were not remarkable, in our study, two infants developed seizures associated with $\mathrm{Ca}$ level $<7 \mathrm{mg} / \mathrm{dL}$. Similar findings occurred in two previously mentioned studies, wherein one infant had developed apnea, ${ }^{5}$ and in another study, three infants had developed significant hypocalcemia. ${ }^{18}$

On the basis of these results, it might be prudent to use a hat, which is a safe, cheap, and effective method for preventing phototherapy-induced hypocalcemia.

Table 3 Comparison between the number of neonates who developed hypocalcemia and jitteriness

\begin{tabular}{llll}
\hline Variable & $\begin{array}{l}\text { Without } \\
\text { hat, } \mathbf{N = 6 2}\end{array}$ & $\begin{array}{l}\text { With hat, } \\
\mathbf{N}=\mathbf{6 2}\end{array}$ & P-value \\
\hline Hypocalcemia & $15(24.2 \%)$ & $6(9.7 \%)$ & 0.031 \\
Normal Ca level & $47(75.8 \%)$ & $56(90.3 \%)$ & \\
Jitteriness & $12(19.4 \%)$ & $6(9.7 \%)$ & 0.12 \\
No jitteriness & $50(80.6 \%)$ & $56(90.3 \%)$ & \\
\hline
\end{tabular}

Although no studies comparing the use of a hat to calcium supplementation have been conducted so far, using prophylactic calcium supplementation can cause some side effects. Some individuals who take calcium supplements might experience gastrointestinal side effects, including gas, bloating, constipation, or a combination of these symptoms. Calcium carbonate appears to cause more of these side effects than calcium citrate. ${ }^{19}$

No side effects were detected from using hat during this study. Hat is the safest method for prevention of phototherapy-induced hypocalcemia as it is a noninvasive method and maintains the normal and physiological pattern of melatonin secretion.

Some limitations met us during this study. These limitations included the small sample size and the single study center, whereas the effects and management of phototherapyinduced hypocalcemia need to be observed on different populations; the need for close contact with cases during phototherapy to ensure that the hat was used all the time, except during feeding; and the need for the detection of the clinical signs of hypocalcemia, which might have not been feasible all the time, due to the shortage of our nurses. In addition, nonspecific jitteriness can present in the neonatal period and can be mistaken as a sign of hypocalcemia.

Although this study was conducted on full-term neonates, it seems logical to apply the hat on preterm neonates as well, as the incidence of phototherapy-induced hypocalcemia is higher in the latter than in full-term neonates. ${ }^{16}$ This may be due to the higher penetration of light in premature infants. ${ }^{17}$

Future studies including preterm and full-term neonates, comparing the results between treatment covering the heads and prophylactic calcium supplementation, will strength our results.

\section{Conclusion}

Phototherapy-induced hypocalcemia was well evident in our study, and although the signs were not remarkable, some infants developed complications. On the basis of these results, it might be prudent to use a hat, which is a safe, cheap, and effective method for preventing phototherapy-induced hypocalcemia. 


\section{Disclosure}

The authors report no conflicts of interest in this work.

\section{References}

1. Stoll BJ, Piazza AJ. Jaundice and hyperbilirubinemia in the newborn. In: Behrman RE, Kliegman RM, Jenson HB, editors. Nelson Textbook of Pediatrics. 18th ed. Philadelphia: WB Saunders Co; 2007:756-761.

2. Maisels MJ. Neonatal jaundice. Pediatr Rev. 2006;27(12):443-454.

3. Stokowski LA. Fundamentals of phototherapy for neonatal jaundice. $A d v$ Neonatal Care. 2006;6(6):303-312.

4. Ehsanipoor F, Khosravi N, Jalali S. The effect of hat on phototherapy induced hypocalcemia in iicteric newborn. Razi J Med Sci. 2008;15(58): 25-29.

5. Eghbalian F, Monsef A. Phototherapy-induced hypocalcemia in icteric newborns. IJMS. 2002;27(4):162-171.

6. Romagnoli C, Polidori G, Cataldi L, Tortorlo SG, Segni G. Phototherapy induced hypocalcaemia. J Pediatr. 1979;94(5):813-816.

7. Hakanson DO, Penny R, Bergstrom WH. Calcemic response to photic and pharmacologic manipulation of serum melatonin. Pediatr Res. 1981;22:414-416.

8. Tan KL. Phototherapy for neonatal jaundice. Clin Perinatol. 1991;18(3): 423-439.

9. Sethi H, Saili A, Dutta AK. Phototherapy induced hypocalcaemia. Indian Pediatr. 1993;30(12):1403-1406.
10. Hunter KM. Hypocalcemia. In: Cloherty JP, Eichenwald CE, Stark AR, editors. Manual of Neonatal Care. 5th ed. Philadelphia: Lippincott Wiliams \& Wilkins; 2004:579-588.

11. Kim SH, Park JH. Effect of phototherapy on bone metabolism in newborn rats. J Korean Soc Neonatal. 2001;8(2):206-210.

12. Hooman N, Honarpisheh A. The effect of phototherapy on urinary calcium excretion in newborns. Pediatr Nephrol. 2005;20(9):1363-1364.

13. Whaley L, Wong D. Text book of Infant and Pediatric Nursing Care. 4th ed. St Louis: Mosby; 2004.

14. American Academy of Pediatrics, Subcommittee on Hyperbilirubinemia. Management of hyperbilirubinemia in the newborn infant 35 or more weeks of gestation. Pediatrics. 2004;114:297-316.

15. Jain A, Agarwal R, Sankar MJ, Deorari A, Paul VK. Hypocalcemia in the newborn. Indian J Pediatr. 2010;77(10):1123-1128.

16. Jain BK, Singh H, Sing D, Too NS. Phototherapy induced hypocalcemia. Indian Pediatr. 1998;35:566-567.

17. Karamifar H, Pishva N, Amirhakimi GH. Prevalence of phototherapyinduced hypocalcemia. Iran J Med Sci. 2002;27(4):166-168.

18. Kargar M, Jamshidi Z, Beheshtipour N, Pishva N, Jamali M. Effect of head covering on phototherapy-induced hypocalcaemia in icterus newborns; a randomized controlled trial. Int J Community Based Nurs Midwifery. 2014;2(2):121-126.

19. Committee to Review Dietary Reference Intakes for Vitamin D and Calcium, Food and Nutrition Board, Institute of Medicine. Dietary Reference Intakes for Calcium and Vitamin D. Washington, DC: National Academy Press; 2010.

\section{Publish your work in this journal}

Research and Reports in Neonatology is an international, peer-reviewed, open access journal publishing original research, reports, editorials, reviews and commentaries on neonatal health. The manuscript management system is completely online and includes a very quick and fair

\section{Dovepress}

peer-review system. Visit http://www.dovepress.com/testimonials.php to read real quotes from published authors. 